\title{
Parque Infantil: a singularidade e seus componentes ${ }^{1}$
}

\section{Parque Infantil: The Singularity and its Components}

\author{
Moysés Kuhlmann Jr."
}

\begin{abstract}
RESUMO
Este artigo tem como intenção problematizar a atribuição de originalidade da instituição extraescolar denominada parque infantil, integrado ao Departamento de Cultura da prefeitura da cidade de São Paulo em 1935. Apresentam-se articulações e propostas de instituições congêneres, com diferentes denominações. O playground norte-americano e sua história são focalizados no texto. Elencam-se e analisam-se elementos constitutivos dessas propostas. $\mathrm{O}$ texto se apoia em artigos e livros com resultados de pesquisas sobre o tema e em fontes documentais, como reportagens da imprensa diária, relatórios e comunicações a congressos, revistas e livros do período estudado, que retrocede à primeira metade do século XIX. Inspiradas em uma metodologia indiciária, a crítica historiográfica e a interpretação histórica têm como perspectiva situar o estudo da história da educação no quadro das relações sociais. A crítica historiográfica identifica a adoção de narrativas feitas pelos sujeitos que atuaram no período ou o uso das fontes sem problematização, simplificando os processos históricos. A interpretação se distancia de atribuir valor às instituições, seja de forma positiva ou negativa. Considera-se que não basta adjetivá-las como promotoras da cultura e da cidadania, ou ao contrário, do controle e da disciplina, pois ambas as dimensões podem ser identificadas nos elementos presentes nas propostas. A helioterapia e as escolas ao ar livre, o paisagismo e os parques urbanos, a educação física como impulsionadora dos ambientes educacionais ativos e das atividades culturais, as propostas da escola infantil britânica compõem a configuração do parque infantil.
\end{abstract}

Palavras-chave: Parque Infantil. História. Educação. Brasil. Estados Unidos da América.

1 Apoio do Conselho Nacional de Desenvolvimento Científico e Tecnológico (CNPq), bolsa de produtividade. Projeto "Historiografia da educação no quadro das relações sociais: infância e instituições".

* Universidade Católica de Santos. Santos, São Paulo, Brasil. Fundação Carlos Chagas, São Paulo, São Paulo, Brasil. E-mail: mkj@fcc.org.br. https://orcid.org/0000-0001-7564-620X. 


\begin{abstract}
This article intends to problematize the attribution of originality to the non-school institution called parque infantil (childhood park), which was integrated into the Department of Culture of the city of São Paulo in 1935. We present articulations and propositions of similar institutions with different denominations. The text approaches the North American playground and its history. We also list and analyze the elements which form these propositions. The text relies on articles and books with research results about the subject and on documentary sources such as news stories, reports and communications to congresses, magazines and books of the studied period, which goes back to the first half of the nineteenth century. Inspired by an evidentiary methodology, both historiographic critique and historical interpretation aim to place the study of history of education within the framework of social relations. Historiographic critique identifies the adoption of narratives made by individuals who acted during the period, or the use of sources without problematization, which simplifies historical processes. Interpretation avoids valuing institutions, whether positively or negatively. It considers that it is not enough to characterize them as promoters of culture and citizenship, or, to the contrary, as forms of control and discipline, since both dimensions can be identified in the elements present in the propositions. Heliotherapy and open air schools, landscaping and urban parks, physical education as a driving force for active educational environments and cultural activities and the propositions from British Infant School make up the outline of parque infantil.
\end{abstract}

Keywords: Parque Infantil. History. Education. Brazil. United States of America.

\title{
Introdução
}

Parque Infantil foi o nome atribuído na cidade de São Paulo, em 1935, à instituição extraescolar que atendia a uma população infantil entre 4 e 12 anos de idade, vinculada ao recém-criado Departamento de Cultura do município. Essa denominação perdurou até o ano de 1975, quando houve a mudança para Escola Municipal de Educação Infantil. Nessa época, a idade máxima das crianças atendidas já estava restrita aos 6 anos. $^{2}$

2 O nome do órgão passou por mudanças: inicialmente, Departamento de Cultura, depois Secretaria de Educação e Higiene, depois Secretaria de Educação e Cultura e Secretaria de Educação. 
No Brasil, especialmente a partir da década de 1940, o Parque Infantil foi difundido para vários municípios do interior paulista e também para outros estados. Há uma singularidade da instituição que está referida à adoção dessa denominação de forma generalizada e também à trajetória de instituição extraescolar para escolar, com a sua transformação em Escola Municipal de Educação Infantil.

Após instituir a rede de educação pré-escolar, a Secretaria de Educação paulistana projetou a sua origem no passado e estabeleceu que 1935 teria sido a data de início da educação pré-escolar municipal paulistana, comemorando suas efemérides, embora por um longo período o parque infantil tivesse uma configuração distinta, por atender uma faixa etária mais ampla do que a da pré-escola (ESCOLA MUNICIPAL, 1985; MAGISTÉRIO, 2015).

Parte das pesquisas sobre a história do parque infantil paulistano considera Mário de Andrade como o seu idealizador, chegando a hipertrofiar o seu papel nas definições das propostas para a instituição, sendo frequente encontrar nos textos a expressão: "os parques infantis de Mário de Andrade" (ABDANUR, 1994; DANAILOF, 2006; FARIA, 1995; FONSECA; FERREIRA; PRANDI, 2015; GOBBI, 2012, entre outros). Outros estudos ressaltam o papel de Nicanor Miranda, que foi o responsável direto pela seção dos Parques Infantis (depois Divisão de Educação, Assistência e Recreio) até o ano de 1946 (FILIZOLLA, 2002; GOMES, 2013; SILVA, 2008).

A primeira interpretação apoia-se nas narrativas produzidas pelos envolvidos na idealização e implementação do Departamento de Cultura, como Paulo Duarte, em suas memórias, bem como em alguns escritos de Mário de Andrade sobre infância e cultura, que estão indiretamente relacionados à organização e à formulação das propostas para os parques.

Quanto a Nicanor Miranda, ele mesmo fomentou o seu papel de protagonista, atribuindo-se tanto a iniciativa da denominação da instituição quanto da elaboração de uma proposta diferenciada das instituições congêneres.

Este artigo tem como intenção problematizar a atribuição de originalidade do Parque Infantil, tanto no que se refere à sua denominação quanto às propostas e concepções educacionais. A interpretação se distancia de atribuir valor às instituições, seja de forma positiva ou negativa. Considera-se que não basta adjetivá-las como promotoras da cultura e da cidadania, ou ao contrário, do controle e da disciplina, pois ambas as dimensões podem ser identificadas nos elementos presentes nas propostas. 


\title{
De Playground a Parque Infantil
}

Em relação à denominação, Nicanor Miranda, em entrevista à revista Escola Municipal, em edição comemorativa dos 50 anos da pré-escola municipal, no ano de 1985, afirmou ter sido o responsável pela expressão:

\begin{abstract}
No ato 767/35 está escrito: "considerando que os parques de recreios e jogos..." Foi este o nome que Fernando de Azevedo deu em substituição a "playgrounds" (...). As pessoas confundiam parques de recreio com parques de diversão, e jogos com jogos de azar. Então propus a denominação "Parques Infantis". Existe um processo de minha autoria neste sentido e um ato do prefeito mudando a denominação de "Parques de Recreios e de Jogos" para "Parques Infantis" (p. 58).
\end{abstract}

Nessa justificativa, está expresso o reconhecimento de que a autoria da proposta da instituição foi de Fernando de Azevedo, inspirado no playground norte-americano. Fernando de Azevedo utilizou uma tradução quase literal dos playgrounds, desde o Código de Educação, de 1933, com a expressão "campos de recreios e jogos". Azevedo foi um dos principais colaboradores na proposta de estruturação do Departamento de Cultura paulistano, em que detalhava a organização e o programa arquitetônico das praças de recreio (ABDANUR, 1992; FILIZZOLA, 2002; NIEMEYER, 2002).

Não se encontrou o processo referido por Miranda sobre a mudança do nome, mas é plausível que tenha sido feito, considerando a justificativa dada por ele. Entretanto, Miranda não foi o criador da expressão, já utilizada em 1932, em relatos sobre o primeiro ano de atividades do Departamento de Educação Física do estado de São Paulo (DEF-SP). Em duas reportagens, uma publicada no Estado de S. Paulo e a outra na Folha da Manhã, mencionava-se como realização do DEF-SP a "seleção de locais para a instalação de parques infantis em vários pontos da capital", bem como a propaganda junto a municípios do interior para a instalação de "parques infantis" (DALBEN; GOIS JUNIOR; LIMA; PALMA, 2019, p. 279).

A reportagem da Folha da Manhã indicava que a intenção era criar espaços com a participação de professores. O texto destaca que o DEF-SP teve como primeira preocupação a infância, que selecionou locais, aparelhos para equipar os parques, mas também estudou jogos educativos para a infância, dando-lhes "letra e música mais adequada", além de promover um curso rápido de edu- 
cação física para aperfeiçoamento de membros da Diretoria Geral de Ensino: "Innumeras moças ficaram, por elle, habilitadas a ministrar aulas proveitosas ás crianças de nossas escolas e parques infantis" (ANNIVERSARIO, 1932, p. 12).

Embora o texto utilize a expressão no plural, do que se sabe, havia na ocasião um único parque na cidade de São Paulo, inaugurado em dezembro de 1930 com o nome de "Play-ground" do Parque D. Pedro II (DALBEN; GÓIS JUNIOR; LIMA; PALMA, 2019).

Alguns meses antes dessas notícias, em novembro de 1931, a expressão parques infantis foi utilizada em reportagem publicada no Jornal do Brasil, que falava de outra instituição que antecedeu a paulistana, o Jardim de Recreio de Porto Alegre: "Fundados em 1926 por iniciativa do Prefeito Octavio Rocha e sob a direcção technica do Sr. F. G. Goelzer³, existem em Porto Alegre cinco jardins de recreio ou parques infantis, que são verdadeiros centros de educação physica moderna" (JARDINS DE RECREIO..., 1931, p. 16).

Parque Infantil, portanto, não foi uma expressão criada por Nicanor Miranda, tendo sido utilizada como correspondente a Playground, Praça, Parque ou Campo de Jogos, Jardim de Recreio, denominações utilizadas em diferentes situações, referidas à implantação dessa modalidade extraescolar, sendo que em 1931, o playground do Parque D. Pedro II recebeu um novo nome: Escola de Saúde.

Em 1930, Maria Antonieta de Castro, diretora secretária da associação Cruzada Pró-Infância, que tinha Pérola Byington como diretora geral, desenvolveu um modelo de programa destinado à infância que tinha por propósito diminuir a mortalidade infantil e promover a educação para a saúde física e moral das crianças. A proposta foi encaminhada no sentido de fazer com que o playground do Parque D. Pedro II de maneira mais eficiente. Em março de 1931, o prefeito Anhaia Melo estabeleceu uma parceria com a Cruzada, que passou a administrar o playground com a nova denominação (BRITES, 1999; MOTT; BYINGTON; ALVES, 2005). Castro escreveu, em relatório da associação:

Em 1931, a Cruzada organizou e fêz funcionar, no Parque D. Pedro, a "Escola de Saúde", para débeis físicos, com regime especial de exercícios físicos, hidro e helioterapia, na qual organizou, também, a primeira Bibliotéca Infantil de S. Paulo, com 500 volumes. Em 1936, assimilada pela Prefeitura, esta Escola se transformou no Parque Infantil que, ainda, existe (CASTRO, 1956, p. 2).

3 O sobrenome correto é Gaelzer. 
As propostas para a implantação do playground nas terras paulistanas remontam à década de 1920. O médico Edmundo de Carvalho, que depois veio a ser diretor do Instituto de Educação Física do Estado, foi contemplado em 1922 com a concessão de um terreno pela prefeitura, no bairro da Água Branca, para ali instalar o Instituto de Cultura Physica da Infância, por meio da Lei n ${ }^{\circ} 2553$ (DALBEN, 2016, p.19). Em 1929, a Lei n ${ }^{\circ} 3371$, Artigo $1^{\circ}$, subvencionou o Instituto com a quantia de 120 contos de réis para a construção do playground no Parque D. Pedro II. Carvalho era à época presidente do Rotary Club de São Paulo (SÃO PAULO, 1929).

As articulações para essa iniciativa desenvolveram-se ao longo de 1928 e 1929, em reuniões do Rotary, com a participação do futuro prefeito, Luiz Ignácio de Anhaia Mello, urbanista que defendia a proposta de recreios ativos e organizados nas cidades modernas (DALBEN, 2016).

Mas isso não foi feito apenas na capital. A cidade de Santos, no litoral paulista, também despontou como uma referência até então não identificada como precursora. A Escola de Saúde santista, sob a égide do Rotary Club da cidade, foi inaugurada no dia 23 de fevereiro de 1931, para ser depois incorporada à prefeitura, com a denominação de Parque Infantil, em 1942 (CUNHA, 2018).

No relatório encaminhado ao prefeito de Santos, Elias Machado, a diretoria do Rotary santista felicitava o apoio que agora recebia dos poderes públicos, indicando que a proposta se inspirava no "exemplo de S. Paulo, onde o dr. Edmundo de Carvalho, quando presidente do Rotary Clube, organizou a primeira Escola de Debeis". O texto também mencionava o secretário do interior, Arthur Neiva, que havia se comprometido a nomear "as educadoras sanitarias estaduaes, que se incumbirão da disciplina escolar e da instrucção das adjuntas" (ESCOLA DE DEBEIS, 1931).

Cabe destacar que as notícias sobre a Escola de Saúde santista foram publicadas no Diário Nacional, órgão do Partido Democrático, jornal em que Nicanor Miranda trabalhava como redator, desde 1928, convidado por Paulo Duarte. Na entrevista concedida em 1985, Nicanor afirmou que com a fundação do Rotary Clube, ele havia sido indicado para escrever as notícias das suas reuniões. Em uma delas, assistiu a uma palestra do então prefeito de São Paulo, Pires do Rio, que destacou a importância dos playgrounds. Sensibilizado, Nicanor afirmou que a fala o fez recordar da visita que fizera às "Plazas de Juegos para Niños", na Argentina, e que teria escrito sobre a palestra, mencionando que Argentina e Uruguai estariam à frente do Brasil, em relação a essa questão (ESCOLA MUNICIPAL, 1985, p.57).

No Diário Nacional do dia 08 de junho de 1929, há uma reportagem sobre a reunião do Rotary, mencionando que após uma palestra de Anhaia Mello sobre o recreio nas sociedades modernas, interveio o prefeito Pires do Rio para 
destacar a realização das obras para o primeiro playground de São Paulo, no Parque D. Pedro II, com a intenção de se criar playgrounds em "locaes como o Jardim da Luz, as nascentes do Ipiranga, o sitio do Ibirapuera e as margens do Tamanduatehy" e ressaltar a importância da "direcção dos parques" (ROTARY, 1929). Não se localizou, no jornal, o texto sobre as plazas de juegos.

Nos seus escritos, Miranda referiu-se a antecedentes e ao histórico dos playgrounds em diversos países, mas o processo histórico aparece de forma truncada. Arrolam-se concepções pedagógicas e experiências que fundamentariam a proposta do Parque Infantil. A instituição seria uma ideia "recomendada pelos mais eminentes sociólogos, médicos e educadores contemporâneos e experimentada por algumas das nações mais civilizadas do globo" (1938, p.8). Mas o texto silencia em relação ao passado paulistano e de outras localidades, tratando as demais iniciativas nacionais de forma lacônica, ou até mesmo desqualificando-as. Com isso, a ideia parece ter brotado dessas referências externas e se concretizado em nosso país apenas a partir de 1935. A sua atuação marcaria então, um momento inaugural, que instituiria profundas transformações nas experiências existentes, como afirmou em palestra na inauguração do Parque Infantil de Santo Amaro:

Em princípios de 1935, o prefeito Fabio Prado criava o Serviço de Parques Infantis, convidando-nos para organizá-los e dirigi-los. (...)

Os Parques eram, então, campos de jogos, com abrigos, galpões e aparelhos de recreio. Eles viriam a ser aquilo que idealizávamos num conceito nosso: logradouros públicos onde, pela recreação e pelo jogo organizado, se procura educar a criança, ministrando-lhe simultaneamente toda a assistência necessária (MIRANDA, 1938, p. 19).

A assistência se desdobraria como médica, dentária e alimentar. A educação visaria o desenvolvimento físico, intelectual e social, por meio da educação física, jogos, biblioteca, jornais e clubes. No mesmo sentido, a recreação se faria nas atividades de música, teatro, desenho, trabalhos manuais e excursões (MIRANDA, 1938).

Em livro sobre a propagação dos parques infantis, a especificidade do parque paulistano foi justificada citando contato com o responsável pela organização dos Parques Infantis em Paris:

Ao contar ao dr. Le Meé a organização dos Parques Infantis de São Paulo, com assistência médica completa, distribuição gratuita de merenda, serviços organizados de educação física, educação higiênica e recreação, 
regalos que a Prefeitura de São Paulo faz aos pequenos munícipes dos bairros proletários, ele nos olhava com certo espanto, como quem não pudesse acreditar que no Brasil houvesse uma cidade com parques infantis organizados, como não vira muitos nem mesmo nos Estados Unidos.

Não sabemos se ao receber, há três anos, uma coleção de fotografias que lhe enviamos, o seu olhar de nobre francês teve outra expressão e os seus gestos de fidalgo acenaram de admiração ou de entusiasmo diante de documentário que comprovava a realização, pela cidade de São Paulo, de um ideal do qual ele era o mais ardoroso partidário e o mais fiel apóstolo (MIRANDA, 1941, p. 10).

Além do exagero no uso do adjetivo completa, para se referir à assistência médica, bem como a necessidade de aferição do que efetivamente se oferecia como merenda, há que se ponderar a quantidade restrita de sete parques e um recanto infantil na cidade de São Paulo, à época em que o trabalho foi escrito. A assistência médica, dentária e alimentar também não foram uma criação do parque infantil. A reportagem sobre a inauguração da Escola de Saúde, em Santos, já mencionava que as crianças receberiam esse tipo de atendimento (ESCOLA DE SAÚDE..., 1931).

Miranda atribuía como diferencial dos parques paulistanos a presença de um corpo profissional e do jogo organizado. Esse argumento foi utilizado para manifestar sua opinião negativa sobre os parques gaúchos:

Existem no Rio Grande do Sul 37 Parques. 1 em Porto Alegre e 26 no interior do Estado. ${ }^{4}$ Não tivemos ainda oportunidade de visitá-los mas supomos que as ideias correntes no Uruguai, onde existem parques organizados com pessoal especializado e parques sem direção, tenham estes últimos influenciado nocivamente a administração gaúcha que os criou (MIRANDA, 1941, p. 22).

O autor justificou a emissão do seu juízo, mesmo sem ter visitado os parques, referindo-se à verba do orçamento do município de Porto Alegre, considerada "irrisória" para "satisfazer as necessidades de um serviço ainda mesmo rudimentar". Ao mesmo tempo, omitiu, em seu texto, a informação de que os parques porto-alegrenses teriam sido precursores em relação à expe-

4 A soma incorreta terá sido um erro de impressão, seriam 11 em Porto Alegre, pois na palestra de 1938, Miranda mencionava que em 13 praças de Porto Alegre foram colocados aparelhos de recreio para as crianças (p. 17). 
riência paulistana. De acordo com Feix e Goellner (2008), o primeiro Jardim de Recreio era constituído por salas para jardim de infância, biblioteca e vários equipamentos na área externa.

Uma reportagem publicada no Jornal do Brasil, em 1931, indicava os elementos que compunham os Jardins de Recreio, providos de aparelhos ginásticos para a prática do atletismo, na seção masculina, de aparelhos recreativos para meninas e meninos, "canchas" para jogos organizados, como basquete, vôlei, basebol e outros, tendo a direção técnica de um instrutor e de uma professora especializada. Mas havia também um vínculo com o sistema educacional:

Para cooperar com o Estado na educação physica de nossa infancia, quiz a Prefeitura localizar cada Jardim nas proximidades de uma escola publica. (...)

Com o intuito de attender também ás crianças frequentadoras dos Jardins, em idade pre-escolar, organizaram-se ahi, em pavilhões apropriados, classes de Jardim de Infancia, onde, a par de jogos recreativos especiaes, adoptam-se praticas educativas froebelianas e montessorianas, rodeando-se os pequeninos das influencias mais favoraveis ao seu desenvolvimento (JARDINS DE RECREIO..., 1931, p. 16).

A referência norte-americana foi fundamental para a sua implantação, pois Gaelzer passou uma temporada de seis anos nos EUA, entre 1916 e 1925, formando-se na Associação Cristã de Moços norte-americana, com estágios, ao final da temporada, no México e no Uruguai. Os vínculos entre a $Y M C A$ e a Playground Association of America, criada em 1907, foram intensos (FEIX; GOELLNER, 2008; GOMES, 2006).

Até aqui, fica evidente a relação do parque infantil com seu precedente norte-americano, o playground, comprovada nas trajetórias dos envolvidos e nos processos históricos em que aparecem as diferentes denominações, como praças ou campos de jogos, jardins de recreio, escolas de saúde. Na sequência, serão elencados e analisados elementos constitutivos dessas propostas, no âmbito do higienismo, do urbanismo, da educação física e da pedagogia.

\section{Higienismo}

A Escola de Saúde, na cidade de São Paulo, como referido no relatório de Maria Antonieta de Castro, oferecia exercícios físicos, hidro e helioterapia. 
Em relação à Escola de Saúde santista, o relatório encaminhado ao prefeito em 1931 afirmava:

Neste local serão administrados por educadoras sanitarias estaduaes, auxiliadas por adjuntas municipaes, ás crianças matriculadas, ensinamentos de gymnastica respiratoria e sueca, recreio instructivo, instrucção civica e noções de cousas e de hygiene, além da pratica da helioterapia (ESCOLA DE DEBEIS, 1931).

A menção às crianças débeis e à helioterapia remete às propostas elaboradas pelo movimento higienista, evocando as Escolas ao Ar Livre ou as Escolas ao Sol, difundidas desde o final do século XIX para a cura ou a prevenção da tuberculose, em tempos anteriores ao BCG (AMARAL, 2016).

Essas propostas aparecem no Brasil na revista Educação e Pediatria, fundada em 1913, por Franco Vaz, diretor da Escola Premunitória 15 de Novembro, e por Álvaro Reis, médico do Hospital de crianças do Rio de Janeiro, e também nos estatutos do Departamento da Criança no Brasil, dirigido por Arthur Moncorvo Filho (NOSSO RUMO, 1913; ARCHIVOS DE ASSISTENCIA Á INFANCIA, 1923).

Em 1916, Moncorvo Filho, também diretor do Instituto de Proteção e Assistência à Infância do Rio de Janeiro, apresentou comunicação ao Primeiro Congresso Médico Paulista sobre as iniciativas brasileiras em relação à helioterapia. Destacou, além da sua atuação, os nomes de "Clemente Ferreira, Alfredo Ferreira de Magalhães, Augusto Paulino, V. Veiga, Jader de Azevedo, Ribeiro de Castro, Oliveira Botelho, Julio Novaes e outros", que há três anos começavam a ensaiar o "novo methodo naturista" (MONCORVO Fo, 1917, p.8). No texto, referiu-se à criação de um Serviço especial de helioterapia, com a instalação de solário no Dispensário Moncorvo, apresentando resultados de 14 casos de tratamento de crianças e adolescentes.

Em 04 de maio de 1924, Moncorvo Filho, juntamente com Alves Filgueiras, inaugurou o "Heliotherapium", "um estabelecimento especialmente consagrado á prophylaxia e á cura das doenças pelos banhos de sol”. No discurso proferido na inauguração, Moncorvo afirmou que um dos principais objetivos do instituto estaria em:

(...) cuidar particularmente das creanças debeis, apoucadas, anemicas ou rachiticas, a serem radicalmente transformadas no seu physico pelos 
maravilhosos efeitos da vida ao grande ar, outrossim aprendendo ou brincando sobre o influxo dos raios methodica e escrupulosamente empregados (MONCORVO F ${ }^{\circ}, 1924$, p. 6-7).

O instituto ocupava uma área de $3440 \mathrm{~m}^{2}$ e uma parte significativa do espaço foi projetada como um "Parque" para crianças débeis, em que haveria:

(...) a administração da gymnastica natural pelo methodo de Hebert, proclamada com todo o enthusiasmo e de efficacia sem igual por vários observadores, entre os quaes nas primeiras linhas figuram Armand Dellille e Paul Carton, Genevrier, Dufestel e Perron, no estrangeiro e, entre outros, Almir Madeira e Fabio Luz em nosso paiz" (MONCORVO $\mathrm{F}^{\mathrm{o}}, 1924$, p. 9-11).

Em relação à educação física, o discurso de Moncorvo Filho indica a sua filiação à produção francesa e associa o "methodo naturista" (mencionado no texto de 1916, referido à terapia pelo sol) à "gymnastica natural" de Hébert.

Dalben (2009) refere que Georges Hébert, oficial da marinha francesa, desenvolveu seu método com base na atenção aos povos nativos latinos e na admiração de seus corpos e destrezas. Menciona que Fernando de Azevedo destacou o método natural como um complemento adequado para as atividades escolares, mas que Nicanor Miranda havia polemizado em relação às propostas de Hébert, considerando, por um lado, que o resultado do instinto primário da criança levaria à prática do jogo e não da ginástica, valorizando então as propostas da Escola Nova, assim como, por outro lado, que as propostas de exercícios naturais, referidos ao selvagem, seriam inadequadas, por não condizerem com o progresso e a civilização e por supor que a natureza não necessitaria ser corrigida.

\section{Urbanismo}

Em relação à arquitetura, urbanismo e paisagismo, Gutman e ConinckSmith consideram que: 
Esta transformação - esta demarcação de um espaço público especializado para as crianças urbanas - constituiu uma mudança radical na forma das cidades. (...) Com relação à criança urbana, calorosos debates explodiram no final do século XIX e início do século XX, quando seus defensores se confrontaram com as autoridades públicas em relação à arquitetura e design de ambientes para as crianças, associando formas físicas a diferentes propósitos sociais e políticos. (...) Alguns defensores da criança interpretaram a oferta de parques infantis como parte de uma crítica urbana mais ampla, levando-os a serem refúgios para as crianças, com foco na saúde, na natureza e no potencial humano. Outros tiveram ambições didáticas e disciplinares, na expectativa de que o espaço físico direcionasse o desenvolvimento físico e mental (2004, p. 133). ${ }^{5}$

Já se mencionou neste artigo os debates realizados nas reuniões do Rotary Clube, que previam a instalação de parques e playgrounds na capital paulista e em outros municípios, estudados por André Dalben (2016). Niemeyer (2002) discorreu sobre a relação entre o urbanismo moderno e a recreação, sugerindo que do movimento dos parques norte-americanos, iniciado com os projetos de Frederick Law Olmsted, teria decorrido a proposta dos playgrounds organizados.

Os projetos de Olmsted para o Fort Green Park, em 1867 e para o Buffalo Park, em 1872, já previam espaços denominados como playgrounds, o primeiro com espaços separados para meninos e meninas (PETTENA; ALEX, 1996). ${ }^{6}$

Mas a historiografia do playground nos EUA adota, muitas vezes, a narrativa difundida pela Playground and Recreation Association of America, em 1925, que situa o início do movimento de recreação como resultado da visita de Marie Zakrzewska a Berlin, quando observou jardins com areia para as crianças, implantados pelo líder político Von Schenkendorf. Posteriormente, ela teria descrito a iniciativa para membros da Massachusetts Emergency and Hygiene Association, que instalou um amplo tanque de areia nos jardins da Children's Mission em Boston, em 1885 (HANSAN, 2013).

\section{Educação Física}

O movimento dos playgrounds norte-americanos abarcou um conjunto de modalidades, instalados em parques públicos, em escolas ou adjacentes a elas,

5 As traduções do inglês no artigo foram feitas pelo autor.

$6 \mathrm{O}$ projeto pode ser consultado no endereço: http://historicfortgreene.org/history-of-fort-greene/fort-greene-park. 
em edifícios, em jardins de infância ou para pré-escolares, tanto para atividades mais livres (embora com a presença de um professor ou supervisor) quanto para atividades mais dirigidas, como aquelas organizadas para os períodos de férias escolares (PLAYGROUND ASSOCIATION OF AMERICA, 1909).

Vinculado à área da Educação Física, o movimento também remete à organização dos recreios nas escolas, com a edificação de pátios para atividades esportivas e recreação. Associados a essas propostas estão o escotismo, a organização de acampamentos e de colônias de férias, a formulação de regras para as modalidades esportivas e a construção de quadras e praças de jogos.

Niemeyer (2002) destacou os intercâmbios de Miranda com a associação norte-americana, mas sugerindo que os parques paulistanos seriam diferentes, pois

não tinham objetivos meramente higiênicos ou disciplinares (...) o objetivo era anexar um pacote de iniciativas culturais, visando assistir os parqueanos sob os aspectos não somente físicos, mas, sobretudo, expandir processos educativos e culturais desde a mais tenra idade. Não por acaso, seu programa pedagógico contará com o apoio de educadores de peso, como Fernando de Azevedo (...); fator que o diferenciava entre os congêneres estrangeiros, mais inclinados a uma assistência de caráter pedológico (sic) (p. 107).

O playground norte-americano não teria sido um movimento com objetivos somente higiênicos ou disciplinares, pois abarcaria propósitos educativos e culturais a que o próprio Nicanor Miranda prestou o seu tributo:

A educação física moderna no seu novo e amplo conceito norte-americano e não no conceito acanhado e estreito de algumas escolas europeias, contém, envolve e subentende assistência médica, exames periódicos de saúde, clínicas de nutrição, regimes dietéticos, serviço social e pesquisas científicas relativas ao educando, sua família e respectiva (sic) condições mesológicas. Todos os trabalhos nos Parques Infantis de S. Paulo visam realizar aqueles ideais modernos de educação que alguns cientistas contemporâneos resumem em saúde, beleza, bondade e sabedoria, ou vitalidade, coragem, sensibilidade e inteligência, fórmulas ambas que no fundo se encontram (MIRANDA, 1941, p. 21). 
Artigo editorial da revista Playground, em junho de 1907, após a primeira convenção da Playground Association of America (PAA), trata das escolas de jogos (play schools) do ponto de vista da filosofia ou dos valores educacionais. As escolas de jogo congregariam playgrounds, fazendas de jogos (play farms), escolas de férias e suas lojas:

As escolas de jogos são necessárias para o desenvolvimento da expressão, poder, personalidade - metade do trabalho da educação pública elementar, ignorada ou pouco desenvolvida no atual sistema de educação, que limita sua atenção majoritariamente para o trabalho de pensamento, refinamento, cultura (STEWART, 1907, p. 7).

Os ideais modernos de educação, mencionados por Miranda, parecem ter sido extraídos de um diagrama do artigo, que contrapõe, a cada elemento do caráter desenvolvido nas escolas, outro mais ativo, que seria trabalhado nas escolas de jogo, com base em princípios fundamentais ligados às sensibilidades do indivíduo, hábitos ou componentes intelectuais fundamentais e elementos da vontade ou determinação. A metade desenvolvida corresponderia ao percurso que segue da alfabetização ( $A B C$ classes) ao ensino secundário (Grammar Schools), enquanto a metade atrasada iria do kindergarten ao kinderwelten, do jardim da infância ao mundo da infância. Os ambientes educacionais ativos poderiam ser incorporados às contribuições do ensino elementar, com ambientes educacionais passivos, para o necessário complemento da formação do caráter (STEWART, 1907).

O folclore foi um dos recursos recomendados pela PAA. No Segundo Congresso Anual de Playgrounds, ocorrido em 1908, em Nova Iorque, o festival de danças nacionais e folclóricas foi considerado o mais belo evento da reunião. As danças folclóricas apresentadas pelas crianças eram oriundas de várias nacionalidades: italiana, polonesa, espanhola, irlandesa, boêmia, russa, sueca, húngara, escocesa, alemã e "negro" (sic) (PLAYGROUND ASSOCIATION, 1908, p. 48-49).

A dança folclórica proporcionaria situações controladas em que o reconhecimento das diferenças culturais da população imigrante seria um meio para a sua integração à sociedade americana. Ao sentir que suas heranças culturais eram apreciadas, os recém-chegados poderiam desenvolver mais facilmente a lealdade à nova nação. Ao dançar em conjunto, cresceriam menos apegados às suas diferenças e mais conscientes do seu esforço individual como subordinados aos interesses do grupo (MOONEY-MELVIN, 1983). 
Luther Halsey Gulick, presidente da PAA, considerava que não bastaria considerar os jogos e danças como uma válvula de segurança, como de valor moral que dariam a oportunidade para um inocente consumo de alegre energia:

Eles constituem, acreditamos, uma força moral positiva, uma agência social, que tiveram no passado e estão destinados a ter no futuro a grande função de moldar em um todo único aqueles cujas condições e ocupações são demasiadamente diversas (1909, p. 433).

A associação teve seu nome alterado para Playground and Recreation Association of America, em meados da década de 1910, e para National Recreation Association, nos anos de 1930. A retirada do nome Playground teria representado o final da defesa dos playgrounds organizados para as crianças, com a transição para a ênfase no playground como espaço de exercícios de ginástica ou de recreação, nas escolas ou parques públicos, embora a proposta original tenha permanecido no interior das escolas de educação infantil (FROST; WOODS, 1998).

\section{Pedagogia}

Além da concepção moderna da educação física, Miranda considera as ideias de Froebel para o jardim de infância como uma referência remota para o parque infantil. Mas há indícios que remetem a proposta anterior.

$\mathrm{Na}$ historiografia do playground norte-americano, propagou-se uma gravura da Infant School inglesa que, provavelmente foi publicada pela primeira vez no livro A system for the education of the young, de 1840, da autoria de Samuel Wilderspin, fundador da Infant School Society, em 1824 (KUHLMANN JR., 2001; STEWART; MCCANN, 1967, p. 259). As propostas da Infant School propagaram-se por toda a Europa, tendo até mesmo sido adaptadas para implantação das Salles d'Asile na França (CROOK, 1999; KUHLMANN JR., 2010; LUC, 1999).

Em 1993, a imagem apareceu em publicação intitulada O livro completo do playground, mas na sua apropriação, deixou de ser associada à instituição britânica. Em capítulo sobre o desenvolvimento histórico e a evolução dos playgrounds nos Estados Unidos, afirmava-se que seu início permanecia obscuro, 
mas que em fontes antigas da arquitetura, como um livro de Henry Barnard sobre a arquitetura escolar, de 1848, seria possível encontrar a ilustração de um playground para uma escola infantil ou primária. O texto refere que, de acordo com Barnard, a presença de professores no playground seria "absolutamente essencial", mas que também reconhecia a importância da brincadeira livre nesse ambiente, inserindo excertos do que seriam as suas propostas. Os autores comentam que a descrição e a ilustração indicariam o grau de evolução do playground desde meados do século XIX. Barnard, um dos pioneiros do Movimento das Escolas Comuns norte-americano, teria descrito essencialmente um pátio de recreio, enquanto o playground moderno, com seus escorregadores, balanços, gangorras e gaiolas, teria sido criado apenas nas décadas iniciais do século XX (BRETT; MOORE; PROVENZO, 1993, p. 17-19).

Em 2006, Moore reapresenta a figura, afirmando que na longa história dos playgrounds equipados, seria da autoria de Barnard a primeira publicação que ilustrava totalmente esse conceito, pensado como "um espaço pedagógico centrado na brincadeira", apresentando alguns elementos que descrevem aquele espaço (MOORE, 2006, p. 87).

Como em uma brincadeira de telefone sem fio, as apropriações da imagem ganharam novas distorções. Em publicação para apresentar um projeto de design de uma escola portuguesa, ela é reproduzida do texto de Moore, afirmando-se agora que a primeira vez em que o conceito de playground foi proposto e veio à tona foi em 1848, criado por Barnard (ROUYI, 2018). No Brasil, Niemeyer (2002, p. 66), apresenta a mesma imagem (Figura 1) com a legenda "Playground em escola primária nos EUA (1851)", atribuindo a fonte a Pettena (1996), que não tem essa figura em seu livro. Em artigo sobre o tema, Niemeyer considera a imagem como exemplo de um kindergaerten e da inserção de uma tipologia de origem germânica no urbanismo norte-americano (NIEMEYER, 2005).

Mas, como referido na primeira apropriação da imagem, o livro de Barnard não é sobre o playground. Em suas 383 páginas há considerações sobre princípios da arquitetura escolar a serem observados nos projetos das edificações e projetos e plantas para diferentes modalidades educacionais. No prefácio, afirma-se que "esta contribuição para a melhoria dos edifícios e espaços escolares foi originalmente preparada pelo autor em 1838", quando era secretário da Board of Commissioners of Common Schools, em Connecticut. Desde então, Barnard recolheu novos projetos e descrições de edifícios, voltados à causa da educação popular, reunidos em 1848 para a publicação do livro. O autor afirma, inclusive, que "ficaria feliz em receber de qualquer parte, projetos e descrições de novos edifícios escolares, para inseri-los em edições futuras" (BARNARD, 1849, p. 5-6). 
FIGURA 1: A GRAVURA DE WILDERSPIN

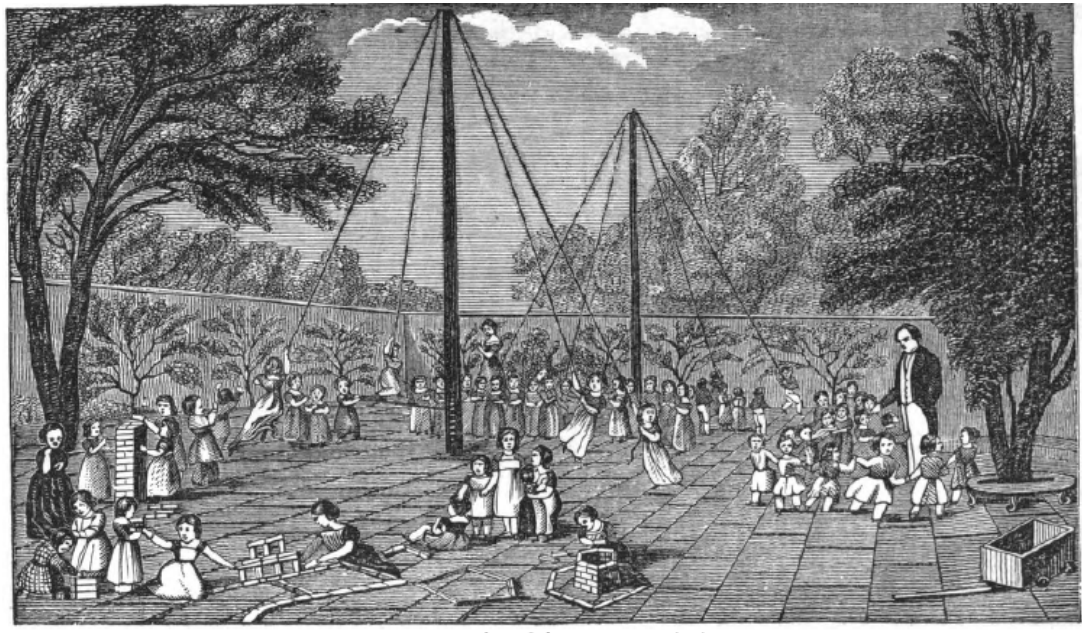

Play. Ground for an Intant or Primary Behool.

FONTE: Segunda edição do livro de Barnard (1849, p.89).

Nas considerações sobre o playground, Barnard afirmava que a figura e a sua descrição foram copiados de livro de Samuel Wilderspin, a quem reverenciou, afirmando que:

Independente do que se pense sobre os métodos de formação intelectual recomendados por este pioneiro do sistema da educação infantil, ninguém pode questionar a utilidade das suas recomendações, para todas as escolas para crianças pequenas, de um playground, externo, seco e aerado, equipado com recursos para uma saudável e inocente recreação, e com floreiras, arbustos e sombra de árvores, em que se ensinará o amor e o respeito às crianças $(1849$, p. 88).

Há uma detalhada descrição da proposta do playground na oitava edição de The infant system for developing the intellectual and moral powers of all children from one to seven years of age de 1852, em que Wilderspin afirma:

Manter uma centena de crianças, ou mais, em uma sala, embora possa ser conveniente sob outros aspectos, mas não para dar rela- 
xamento e exercício apropriado às crianças, que elas não poderiam ter sem um play-ground, seria materialmente ferir a sua saúde, algo, na minha humilde opinião, da primeira importância (WILSDERSPIN, 1852, p. 101).

Na proposta do playground, Wilderspin antecipa o que posteriormente foi formulado por Froebel, do uso de brinquedos de construção como eixo central de sua pedagogia:

Poderíamos providenciar alguns blocos de madeira (...). Com eles as crianças se divertem muitíssimo pela variedade de formas em que podem ser dispostos, e das construções que podem erigir (1852, p. 104-105).

Para ele, o playground da Infant School ficaria completo com a instalação de um balanço giratório. Esse equipamento compõe a imagem de Wilderspin e foi adotado nos playgrounds americanos e também no Brasil, aqui com a denominação de "passo do gigante", que pode ser encontrado em fotos do Jardim de Recreio gaúcho ou do parque infantil paulistano (GOMES, 2006, p. 117; NIEMEYER, 2002, capa).

Ao perscrutar as propostas que convergiram para a criação do parque infantil, encontram-se vários fios, apropriações e transformações. As perspectivas de controle e disciplina, de atividades recreativas e culturais, de desenvolvimento integral, saúde física e mental envolvem diferentes componentes da proposta: o higienismo, o urbanismo, a educação física e a pedagogia.

A interpretação histórica não poderia tomar os documentos como expressão da verdade, pois eles são produtos de relações sociais de seu tempo. Cabe refletir sobre os sujeitos e interesses existentes e sobre as condições em que os documentos foram produzidos, além de considerar como e onde circularam e foram preservados (KUHLMANN JR.; LEONARDI, 2017).

\section{REFERÊNCIAS}

ABDANUR, E. F. Os "ilustrados" e a política cultural em São Paulo: o Departamento de Cultura na gestão Mário de Andrade (1935-1938). 1992. 165 p. Dissertação (Mestrado) - IFCH-Unicamp, Campinas, 1992. 
ABDANUR, E. F. Parques infantis de Mário de Andrade. Revista do Instituto de Estudos Brasileiros, São Paulo, n. 36, p. 263-270, 1994.

AMARAL, Anabela. Aprender a palavra ao ar livre. Estratégias de modernidade sanitária em Portugal no início do séc. XX. História. Revista da FLUP, Porto, v. 6, p. 41-55, 2016. Disponível em: https://ojs.letras.up.pt/index.php/historia/article/view/1716/1524. Acesso em: 22 jan. 2018.

ANNIVERSARIO do Departamento de Educação Physica, O. Folha da Manhã, São Paulo, p. 12, 30 jan. 1932.

ARCHIVOS DE ASSISTENCIA Á INFANCIA, Rio de Janeiro, Typ. J. R. de Oliveira e Comp., v. XII, n. 2, jul. - dez. 1923.

BARNARD, H. School architecture; or contributions for the improvement of schoolhouses in the United States. $2^{\text {nd }}$. ed., New York: A. S. Barnes, 1849. Disponível em: https://books.google.com.br/books?id=7wwyAQAAMAAJ\&printsec=frontcover \&hl $=$ pt-PT $\&$ source $=$ gbs_ge_summary_r $\&$ cad $=0 \# \mathrm{v}=$ onepage $\& \mathrm{q} \& \mathrm{f}=$ false. Acesso em: 04 ago. 2019.

BRITES, O. Imagens da Infância (São Paulo e Rio de Janeiro, 1930 a 1950). 1999. Tese (Doutorado) - Pontifícia Universidade Católica de São Paulo-PUC/SP, São Paulo, 1999.

BRETT, A.; MOORE, R.; PROVENZO, E. The complete playground book. Syracuse, NY: Syracuse University Press, 1993.

CASTRO, Maria Antonieta de. A Cruzada Pró Infância: finalidades, organização, realizações. Relatório apresentado pela Diretora Secretária em 12 de agosto de 1956. São Paulo, 1956.

CROOK, D. L'éducation collective des jeunes enfants en Grande-Bretagne: une perspective historique. Histoire de l'Éducation, n. 82, p. 23-42, mai 1999.

CUNHA, Humberto Pereira da. De Escola de Saúde a Parque Infantil: Santos (19311952). 2018. 119 p. Dissertação (Mestrado) - Unisantos, Santos, 2018.

DALBEN, A. Educação do corpo e vida ao ar livre: natureza e educação física em São Paulo (1930 - 1945). 2009. Dissertação (Mestrado) - Faculdade de Educação Física, Unicamp, Campinas, 2009.

DALBEN, André. Notas sobre a cidade de São Paulo e a natureza de seus parques urbanos. Urbana: Rev. Eletrônica Cent. Interdiscip. Estud. Cid. Campinas (SP), v. 8, n. 2[13] p. 3-27, mai.-ago. 2016.

DALBEN, A.; GÓIS JUNIOR, E.; LIMA, R. J. C.; PALMA, L. P. Criação do Departamento de Educação Física do Estado de São Paulo (1925-1932). Cadernos de Pesquisa, São Paulo, v. 49, n. 171, p. 264-286, jan.-mar. 2019.

DANAILOF, Kátia. Crianças na trama urbana: as práticas corporais nos Parques Infantis da São Paulo dos anos 1930. 2006. 176 p.Dissertação (Mestrado) - FE-Unicamp. Campinas, 2006. 
ESCOLA DE DEBEIS. Diario Nacional, p. 3, 11 jan. 1931.

ESCOLA DE SAÚDE EM SANTOS. Diario Nacional, p. 6, 19 fev. 1931.

ESCOLA MUNICIPAL. v. 18, n. 13, 1985.

FARIA, S. L. G. Origens da rede pública municipal de educação infantil na cidade de São Paulo: o Departamento de Cultura e os parques infantis de Mário de Andrade (19351938). Pro-posições, v. 6, n. 2, p. 34-45, jun. 1995.

FEIX, E.; GOELLNER, S. V. O florescimento dos espaços públicos de lazer e de recreação em Porto Alegre e o protagonismo de Frederico Guilherme Gaelzer. Licere, Belo Horizonte, v. 11, n. 3, p. 1-18, dez. 2008.

FILLIZZOLA, A. C. B. Na rua, a "troça", no parque, a troca. Os parques infantis da cidade de São Paulo na década de 1930. 2002. Dissertação (Mestrado) - Faculdade de Educação, USP, São Paulo, 2002.

FONSECA, S. C.; FERREIRA, D.; PRANDI, M. B. R. O Departamento de Educação Física de São Paulo e a interiorização dos parques infantis: o caso de Ribeirão Preto. História e Cultura, Franca, v. 4, n. 2, p. 237-261, set. 2015.

FROST, J. L.; WOODS, I. C. Perspectives on play in playgrounds. In: FROMBERG, D. P.; BERGEN, D. Play from birth to twelve and beyond: contexts, perspectives, and meanings. New York: Garland, 1998. p. 232-240.

GOBBI, Marcia Aparecida. Conhecimento histórico e crianças pequenas: parques infantis e escola municipal de educação infantil. Educ. Rev., Belo Horizonte, v. 28, n. 2, p. 203-224, jun. 2012. Disponível em: http://www.scielo.br/scielo.php?script=sci arttext\&pid=S0102-46982012000200010\&lng=pt\&nrm=iso. Acesso em: 21 mar. 2017.

GOMES, Christianne Luce. Significados de recreação e lazer no Brasil: reflexão a partir da análise de experiências institucionais (1926-1964). 2006. 322 p. Tese (Doutorado em Educação) - UFMG, Belo Horizonte, 2006.

GULICK, Luther H. Folk and national dances. In: PLAYGROUND ASSOCIATION OF AMERICA. Proceedings of the second annual Playground Congress and Year Book 1908. New York: Playground Association of America, 1909, p. 429-439.

GUTMAN, M.; CONINCK-SMITH, N. Introduction. Good to think with: history, space and modern childhood. In: GUTMAN, M.; CONINCK-SMITH, N. (Ed.). Designing modern childhoods: history, space and material culture of children. New Jersey: Rutgers University Press, 2008, p.1-19.

HANSAN, J. Playground and Recreation Association of America (1925). The beginning of the recreation movement in the United States. Social Welfare History Project, 2013. Disponível em: http://socialwelfare.library.vcu.edu/youth/recreation-movement-in-theunited-states/. Acesso em: jul 2019.

JARDINS DE RECREIO DE PORTO ALEGRE. Jornal do Brasil, 01/11/1931, p. 16. 
KUHLMANN JR., M. O jardim-de-infância e a educação das crianças pobres: final do século XIX, início do século XX. In: MONARCHA, C. (Org.). Educação da infância brasileira: 1875-1983. Campinas, SP: Autores Associados, 2001. p. 3-30.

KUHLMANN JR., M. Relações sociais, intelectuais e educação da infância na história. In: SOUZA, G. (Org.). Educar na infância: perspectivas histórico-sociais. São Paulo: Contexto, 2010. p. 81-98.

KUHLMANN JR., M.; LEONARDI, P. História da educação no quadro das relações sociais. História da Educação, v. 21, n. 51, p. 207-227, abr. 2017.

LUC, J.-N. La diffusion des modèles de préscolarisation en Europe dans la première moitié du XIXe siècle. Histoire de l'Éducation, n. 82, p. 189-206, mai 1999.

MAGISTÉRIO. Secretaria Municipal de Educação. São Paulo: SME / DOT, 2015. [Edição Especial: 80 anos da educação infantil na rede municipal de ensino de São Paulo].

MOONEY-MELVIN, P. Building Muscles and Civics: Folk Dancing, Ethnic Diversity and the Playground Association of America. American Studies, v. 24, n. 1, p. 89-99, Spring 1983.

MIRANDA, N. O significado de um Parque Infantil em Santo Amaro. São Paulo: Subprefeitura de Santo Amaro, 1938.

MIRANDA, N. Origem e propagação dos parques infantis e parques de jogos. São Paulo: Departamento de Cultura, 1941.

MONCORVO FILHO, A. Os primeiros ensaios de heliotherapia no Brasil: trabalho do Dispensario Moncorvo. Rio de Janeiro: Typ. Besnard Frères, 1917.

MONCORVO FILHO, A. Em favor das creanças: a cura pelo sol. Rio de Janeiro: Typ. Besnard Frères, 1924.

MOORE, Robin. Playgrounds: a 150-year-old model. In: FRUMKIN, H.; GELLER, R. J.; RUBIN, I. L. (Eds.). Safe and healthy schools environments. New York: Oxford University Press, 2006. p. 86-103.

MOTT, Maria Lucia, BYINGTON, Maria Elisa Botelho, ALVES, Olga Sofia Fabergé. O gesto que salva: Pérola Byington e a Cruzada Pró-Infância. São Paulo: Grifo, 2005.

NIEMEYER, Carlos Augusto da C. Parques infantis de São Paulo: lazer como expressão de cidadania. São Paulo: Annablume; FAPESP, 2002.

NIEMEYER, Carlos Augusto da C. Uma contribuição para a pesquisa em história do paisagismo: os parques infantis e as ressonâncias da tipologia reform park em São Paulo. Paisagens em Debate, FAU-USP, n. 3, p. 1-16, nov. 2005.

NOSSO RUMO. Educação e Pediatria, v. 1, n. 1, p. 7-20, jun. 1913.

PETTENA, G.; ALEX, W. Olmsted: L'origine del parco urbano e del parco naturale contemporaneo. Firenze: Centro Di, 1996. 
PLAYGROUND ASSOCIATION OF AMERICA. Proceedings of the second annual Playground Congress and Year Book 1908. New York: Playground Association of America, 1909.

ROTARY CLUB. Diario Nacional, p. 6, 08 jun. 1929.

ROUYI, W. Grow with nature. The playground design of Escola do Calvário. Escola Superior de Arte e Design, 2018. Disponível em: http://hdl.handle.net/10400.26/27882. Acesso em: 24 jul. 2019.

SÃO PAULO (CIDADE). Lei no 3.371, de 21 de agosto de 1929. Disponível em: https:// leismunicipais.com.br/a/sp/s/sao-paulo/lei-ordinaria/1929/338/3371/lei-ordinaria-n-3371-1929-autoriza-o-prefeito-a-subvencionar-com-a-quantia-de-120-000-000-o-instituto-de-cultura-physica-da-infancia-para-a-construccao-de-um-play-ground-no-parque-d-pedro-ii-e-da-outras-providencias-1929-08-21-versao-original. Acesso em: 18 jul. 2019.

SILVA, C. C. O álbum "Parques Infantis" como objeto cultural (São Paulo, 1937). 2008. Dissertação (Mestrado) - Faculdade de Educação, USP, São Paulo, 2008.

STEWART, S. T. Kinder-Welten. The Playground, n. 4, p. 7-10, jul. 1907.

STEWART, W.A. C.; McCANN, W. P. The educational innovators: 1750-1880. London: Macmillan, 1967.

WILDERSPIN, S. The infant system for developing the intellectual and moral powers of all children from one to seven years of age. $8^{\text {th }}$ ed., London: J. S. Hodson, 1852.

Texto recebido em 05/07/2019.

Texto aprovado em 19/08/2019.

\section{Errata}

No artigo Parque Infantil: A singularidade e seus componentes, com número de DOI: 10.1590/0104-4060.68371, publicado no periódico Educar em Revista, Curitiba, Brasil, v. 35, n. 77, p. 223-244, set./out. 2019, na página 227.

Onde se lia:

"[... ]A proposta foi encaminhada no sentido de fazer com que o playground do Parque D. Pedro II de maneira mais eficiente [...]"

Leia-se:

"[...] A proposta foi encaminhada no sentido de fazer com que o playground do Parque D. Pedro II fosse usado de maneira mais eficiente [...]" 